\title{
PAPER
}

\section{Idiopathic intracranial hypertension: 12 cases treated by venous sinus stenting}

\author{
J N P Higgins, C Cousins, B K Owler, N Sarkies, J D Pickard
} See end of article for
authors' affiliations

Correspondence to: Dr Nicholas Higgins, Department of Radiology Box 219, Addenbrooke's Hospital, Hills Road, Cambridge CB2 2QQ, UK nick.higgins@. addenbrookes.nhs.uk

Received 9 December 2002 In revised form 26 April 2003

Accepted 1 May 2003
J Neurol Neurosurg Psychiatry 2003;74:1662-1666

Background: The high pressures documented in the intracranial venous sinuses in idiopathic intracranial hypertension $(\mathrm{IHH})$ could be the result of focal stenotic lesions in the lateral sinuses obstructing cranial venous outflow.

Objective: To explore the relation between venous sinus disease and $\mathrm{IIH}$.

Methods: 12 patients with refractory $\mathrm{IH}$ had dilatation and stenting of the venous sinuses after venography and manometry had shown intracranial venous hypertension proximal to stenoses in the lateral sinuses. Intrasinus pressures were recorded before and after the procedure and correlated with clinical outcome. Results: Intrasinus pressures were variably reduced by stenting. Five patients were rendered asymptomatic, two were improved, and five were unchanged.

Conclusions: The importance of venous sinus disease in the aetiology of $\mathrm{IH}$ is probably underestimated. Lateral sinus stenting shows promise as an alternative treatment to neurosurgical intervention in intractable cases. co diopathic intracranial hypertension (IIH) is an uncommon condition of unknown aetiology, arising mainly in young obese women and characterised by severe headache and visual disturbance. Usually resolving spontaneously over months or years, it occasionally leads to chronic disability and visual loss. Management of cases refractory to medical treatment can be difficult, with some patients subjected to multiple or repeated neurosurgical procedures attempting to reduce intracranial pressure. ${ }^{1}$

Regarding the cause of raised intracranial pressure, various pathogenic mechanisms have been considered, including increased cerebrospinal fluid (CSF) production, decreased CSF absorption, idiopathic brain swelling, and idiopathic intracranial venous hypertension. ${ }^{1-3}$ None appears satisfactory on its own but with reference to the last it is well known that IIH can be mimicked by cerebral venous sinus thrombosis and venous outflow obstruction. $^{4-7}$ In practice, however, this is diagnosed infrequently. ${ }^{8}$

Recently the role of venous disease in the aetiology of IIH has been revisited as several groups, using invasive monitoring, have documented high pressures in the venous sinuses in typical cases. ${ }^{9}{ }^{10}$ Sometimes these seem to be secondary to central venous hypertension but they more often appear to be the result of focal stenotic lesions in the lateral sinuses obstructing cranial venous outflow. This has led to the suggestion that undetected intracranial venous hypertension may after all be the substrate for $\mathrm{IIH}^{10}{ }^{10}$ although some investigators have since questioned the validity of their original findings. ${ }^{11}$

We have reported a case of IIH where the usual investigations failed to reveal a cause of raised intracranial pressure but where catheter venography showed high pressures in the superior sagittal sinus proximal to stenotic lesions in both lateral sinuses. ${ }^{12}$ Dilatation of one of these stenoses with a stent effected a reduction in intracranial venous sinus pressures which was accompanied by an immediate and sustained clinical improvement. With this as evidence of a causal relation between venous sinus disease and IIH we have now treated a further 11 patients.

\section{METHODS}

Patients

Twelve patients, all female, mean age 33 years (range 19 to 52 ), were referred to, or were already under the care of, the neurosurgical service at Addenbrooke's Hospital with a diagnosis of IIH. Patients had been diagnosed with IIH if they presented with a syndrome of raised intracranial pressure without ventricular enlargement or an intracranial mass on imaging, with no evidence of venous sinus thrombosis, and with normal CSF constituents.

All patients had documented raised CSF pressure $(>25 \mathrm{~cm}$ $\mathrm{H}_{2} \mathrm{O}$ ), although in some cases this had been several years previously. Seven patients had had lumbar CSF infusion studies. ${ }^{13}$ All patients had had brain computed tomography (CT) or magnetic resonance imaging (MRI) or both, and magnetic resonance venography (MRV).

All patients had intractable headaches and visual disturbance, the duration of symptoms ranging from five months to 12 years. Two patients had severe visual loss. Eight patients had papilloedema, in three described as chronic. In four patients papilloedema had resolved. All had previously received medical treatment under neurological supervision. Most had had repeated lumbar punctures. Five had had CSF drainage procedures (lumboperitoneal or ventriculoperitoneal shunting). One patient had had optic nerve sheath fenestration and bilateral subtemporal decompressions (table 1). None of these surgical procedures had been done less than 10 months before stenting.

\section{Arteriography, venography, and manometry}

All patients had bilateral carotid angiography under local anaesthesia using standard techniques. Cerebral venography and manometry were done, also under local anaesthesia, using a coaxial microcatheter supported by a guide catheter positioned in the internal jugular veins from a common femoral puncture. Pressure measurements were taken throughout the venous sinuses using a transducer referenced to zero at the level of the mid-axillary line. 
Table 1 Demographic data on the patients

\begin{tabular}{|c|c|c|c|c|c|c|c|c|}
\hline \multirow{2}{*}{$\begin{array}{l}\text { Case } \\
\text { No }\end{array}$} & \multirow{2}{*}{$\begin{array}{l}\text { Age } \\
\text { (years) }\end{array}$} & \multirow{2}{*}{$\begin{array}{l}\text { BMI } \\
\left(\mathrm{kg} / \mathrm{m}^{2}\right)\end{array}$} & \multirow{2}{*}{$\begin{array}{l}\text { Duration of } \\
\text { symptoms } \\
\text { (years) }\end{array}$} & \multirow[b]{2}{*}{ Previous procedures } & \multicolumn{2}{|l|}{ Symptoms } & \multirow[b]{2}{*}{ Papilloedema } & \multirow{2}{*}{$\begin{array}{l}\text { Last documented } \mathrm{CSF} \\
\text { pressure }\left(\mathrm{cm} \mathrm{H}_{2} \mathrm{O}\right)\end{array}$} \\
\hline & & & & & Headache & Visual symptoms & & \\
\hline 1 & 34 & 44 & 3 & LPS $\times 6$ & Yes & Blurring & Absent & 25 \\
\hline 2 & 30 & 30 & 1.3 & None & Yes & Sparkling & Present & 35 \\
\hline 3 & 46 & 32 & 4 & None & Yes & Decreased acuity & Chronic & 30 \\
\hline 4 & 49 & 33 & 11 & LPS & Yes & $\begin{array}{l}\text { Obscurations, constricted } \\
\text { fields }\end{array}$ & Chronic & 40 \\
\hline 5 & 52 & 41 & 12 & $\begin{array}{l}\text { LPS, ONSF, BSTD, } \\
\text { VPS }\end{array}$ & Yes & $\begin{array}{l}\text { Decreased acuity, } \\
\text { constricted fields }\end{array}$ & Absent & 31 (before VPS) \\
\hline 6 & 32 & 45 & 5 & LPS, VPS & Yes & Poor vision & Chronic & 39 (before VPS) \\
\hline 7 & 33 & 30 & 0.4 & None & yes & obscurations & Present & 46 \\
\hline 8 & 24 & 31 & 0.7 & None & yes & obscurations & Present & 30 \\
\hline 9 & 21 & 29 & 1 & None & yes & Constricted fields & Mild & 30 \\
\hline 10 & 19 & 43 & 3.5 & LPS $\times 3$ & yes & $\begin{array}{l}\text { Obscurations, constricted } \\
\text { fields }\end{array}$ & Present & Refused LP \\
\hline 11 & 25 & 42 & 2.3 & None & yes & Blurring & Absent & 40 \\
\hline 12 & 32 & 43 & 5 & None & yes & Blurring, constricted fields & Absent & 25 \\
\hline
\end{tabular}

BMI, body mass index; BSTD, bilateral subtemporal decompressions; LP, lumbar puncture; LPS, lumboperitoneal shunt; ONSF, optic nerve sheath fenestration; VPS, ventriculoperitoneal shunt.

\section{Venous sinus stenting}

Stenting was done under general anaesthesia. A guide catheter was directed into the lateral sinus, usually from a percutaneous jugular puncture, and the stent deployed across the stenosis supported by a guide wire (fig 1). In two patients two overlapping stents were deployed on one side. Ten patients had one side only treated. Two patients (cases 2 and 3) had a second stent placed in the contralateral lateral sinus in a subsequent procedure. Patients were heparinised during the procedure; this was subsequently converted to warfarin, and then to low dose aspirin after eight weeks. In one patient with a thrombophilic disorder, anticoagulation in the long term was recommended. Follow up venography and manometry were usually undertaken once anticoagulation was discontinued.

\section{Outcome assessment}

Except for one patient (case 10) who had gone back to her country of origin, all patients have been kept under ophthalmology review (NS) and under review in a dedicated neurosurgical CSF clinic (JDP). Patients were assessed at 812 weeks, around the time of their follow up venogram, and thereafter in clinic.

With respect to symptoms, patients broadly fell into three categories:

- Asymptomatic: resolution of headache and visual symptoms.

- Improved: some residual headache and/or visual symptoms not requiring further intervention.

- No change: no change in headache or visual symptoms.

The outcome of papilloedema is detailed in table 2 .

\section{RESULTS}

There were no complications from the catheter studies. After stenting, patients usually suffered headache lateralised to the treated side which settled over days to weeks. Two patients complained of transient partial hearing loss on the stented side and one of unsteadiness, all settling within a few days or weeks.

Of 12 patients treated, five have been rendered asymptomatic, two have improved but have residual headache, and five are unchanged (table 2). One patient (case 2), who was improved after treatment, had a second stent placed several months later on the contralateral side with further improvement, but she remains symptomatic. One patient (case 3) who was unchanged after a first procedure subsequently had a stent placed in the contralateral side with initial improvement which was not sustained. No patient deteriorated after stenting. No patient who was asymptomatic or improved at 8-12 weeks has since regressed.

All 12 patients had had papilloedema documented at some stage in their illness. Eight patients still had papilloedema at the time of stenting, and it resolved after stenting in four (in two patients rendered asymptomatic and in two patients who were improved). In one patient (case 4) papilloedema was documented as improved and the patient became asymptomatic. In two patients papilloedema was unchanged; both these patients were symptomatically also unchanged. In one patient (case 10), who was rendered asymptomatic, formal ophthalmic assessment was not done before she went abroad.

Many patients had developed a severe aversion to lumbar puncture by the time they were being considered for active intervention which meant that a systematic approach to CSF pressures was impossible. One patient treated abroad for several years refused lumbar puncture under our care. Another patient (case 2) had infusion studies before and after stenting. In this patient, in whom papilloedema had resolved but who had some residual headache, the opening pressure fell from $21 \mathrm{~mm} \mathrm{Hg}$ before treatment to $14 \mathrm{~mm} \mathrm{Hg}$ afterwards. Other patients had had variably raised CSF pressures (sometimes documented in infusion studies) in the months or years before treatment which were not repeated immediately before stenting. In these cases the minimum likely CSF pressure could be inferred from the venous study. Only one patient (case 2) has had a lumbar puncture after stenting.

Five patients had already had CSF diversion procedures before stenting, and three had had several. Four patients had lumboperitoneal shunts in situ. These had given useful symptom control for a period but then had probably stopped functioning. In these cases minimum CSF pressures before and after stenting could probably be inferred from the venous catheter studies. Two patients had functioning ventriculoperitoneal shunts, with CSF pressures maintained near normal levels but with inadequate symptom control. In these cases intracranial venous pressure might not reflect CSF pressures.

Intrasinus pressure readings were used to guide stent placement at the time of the procedure. However, these pressures and the pressure gradients along the lateral sinuses were changed in an unpredictable fashion with the patient under general anaesthesia from those measured with the 

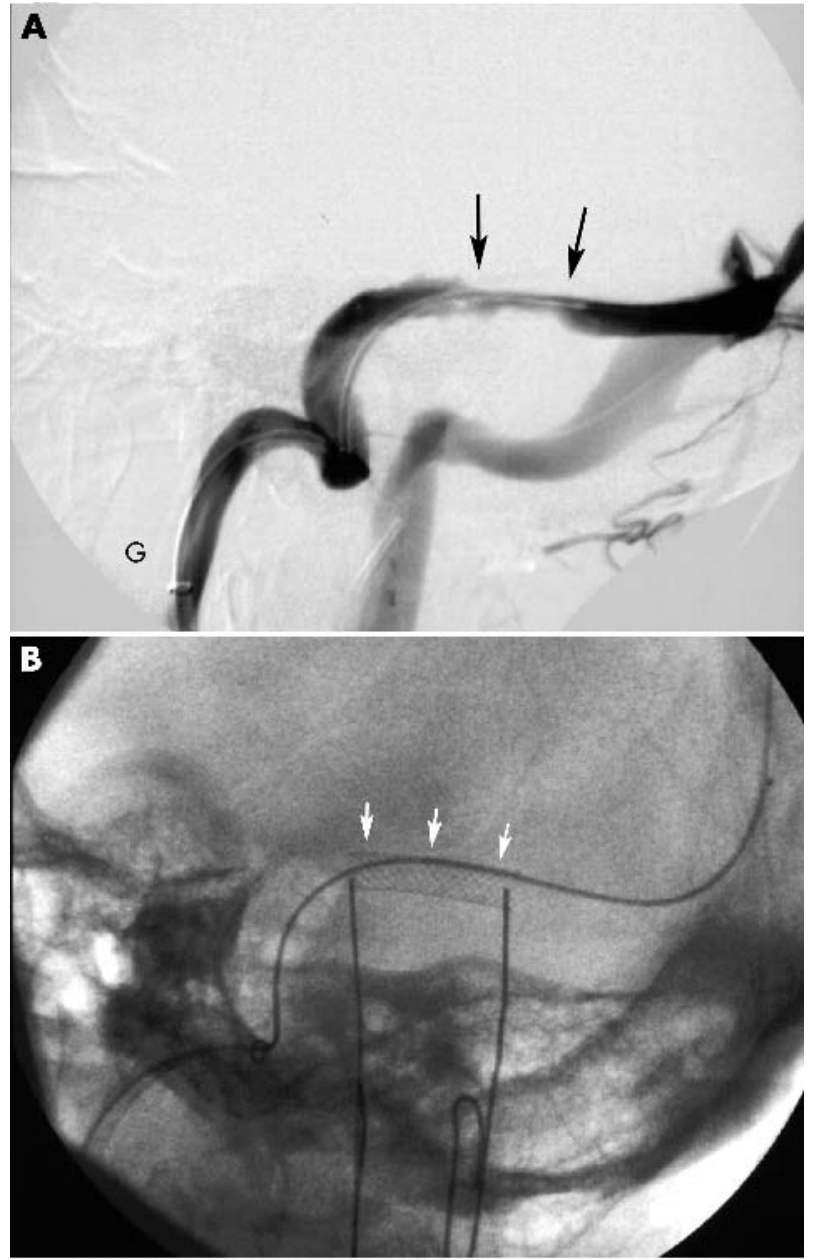

C

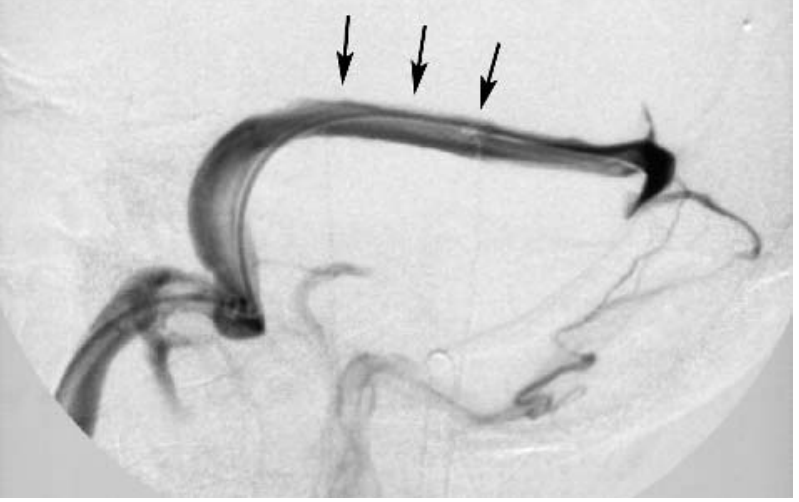

Figure 1 (A) Oblique lateral subtracted venogram of the lateral sinuses. Guide catheter $(G)$ is in the left internal jugular vein. A smaller catheter enters the left sigmoid sinus and crosses the stenosis (arrows) in the left transverse sinus. The right transverse sinus is hidden from view but the right sigmoid sinus and right internal jugular vein are seen. (B) Similar view (unsubtracted) showing guide wire passing through the stent (arrows), deployed at the level of the stenosis. (C) Same view as (B) subtracted venogram showing the site of the stenosis (arrows) dilated by the stent, with good flow through the left lateral sinus.

patient awake. Assessment of the technical success in reducing the pressure gradient in the lateral sinuses was therefore judged by comparing the separate studies done before treatment and at follow up (table 2). All patients had cerebral venography with pressure recordings (manometry) before and after stenting. Some patients had more than one venogram after stenting because of concern over stent patency in the immediate postoperative period. In all these cases the stent was patent, although in two cases thrombolytic treatment was initiated because of intraluminal thrombus. This resolved with treatment, which was accompanied by clinical improvement. In all patients a reduction in intrasinus pressure was achieved, although this was not necessarily accompanied by clinical improvement (table 2 ). In one patient (with a ventriculoperitoneal shunt in situ), this reduction was marginal. She remained symptomatic (case 6).

\section{DISCUSSION}

With IIH partly defined as a condition of unknown aetiology, the radiological investigation of suspected cases is directed towards excluding known causes of raised intracranial pressure. ${ }^{1}$ CT or MRI will rule out hydrocephalus or a space occupying lesion; catheter angiography or MRV will rule out venous sinus thrombosis. ${ }^{14}$ Patients with the characteristic clinical features are diagnosed with IIH once these investigations are found to be normal.

The diagnosis of IIH is therefore founded on the accuracy of the radiological investigations in eliminating alternative pathologies. This accuracy is uncontested regarding the exclusion of an intracranial mass but may be an issue with respect to venous sinus disease. This is pertinent because cerebral venous sinus thrombosis or venous outflow obstruction can cause a syndrome clinically indistinguishable from IIH, and only the radiology may differentiate between them. ${ }^{7}$ MRV has largely replaced catheter angiography here and, in respect of the superior sagittal sinus, produces images that are widely regarded as diagnostic and easy to understand. The lateral sinuses are more difficult, however, with flow gaps and variations in normal anatomy confounding interpretation-a problem not usually resolved with conventional angiography. ${ }^{15} 16$

Recently several groups have circumvented these problems by undertaking catheter studies in the venous sinuses (cerebral venography) and recording intrasinus pressures (manometry). ${ }^{10}$ These groups have documented high pressures in the venous sinuses in patients with IIH, occasionally secondary to systemic venous hypertension but more often apparently the result of stenotic lesions of the venous sinuses, particularly bilateral lateral sinus lesions, causing partial obstruction to cranial venous outflow. This has led some investigators to propose intracranial venous hypertension as the final common pathway in the aetiology of IIH. ${ }^{10}$

These studies are open to varied interpretations, however. The walls of the venous sinuses are compliant and may deform under pressure. Osterholm ${ }^{17}$ and Johnston and Rowan ${ }^{18}$ have shown in the clinical and experimental setting that once intracranial pressure-raised by an intracranial mass lesion-rises above a certain level, pressure in the superior sagittal sinus may also rise owing to secondary collapse of the transverse sinuses. This phenomenon is reversible, with venous hypertension resolving if intracranial pressure is relieved, for example, by craniotomy. High pressures measured in the superior sagittal sinus and the pressure gradients observed along the lateral sinuses in IIH might therefore be a consequence of raised intracranial pressure rather than its cause.

King et al have examined this further. ${ }^{11}$ They found that withdrawing CSF in patients with IIH during cerebral venography (and thereby reducing intracranial pressure) eliminated, or virtually eliminated, the pressure gradients in the lateral sinuses and intracranial venous hypertension. 
Table 2 Venous pressures measured on separate occasions before stenting and 8-12 weeks later; clinical outcome was assessed around the same time

\begin{tabular}{|c|c|c|c|c|c|c|c|}
\hline \multirow{2}{*}{$\begin{array}{l}\text { Case } \\
\text { No }\end{array}$} & \multicolumn{2}{|c|}{$\begin{array}{l}\text { Pressures before stenting } \\
\text { (mm Hg) }\end{array}$} & \multicolumn{2}{|c|}{$\begin{array}{l}\text { Pressures after stenting } \\
(\mathrm{mm} \mathrm{Hg})\end{array}$} & \multicolumn{2}{|c|}{ Clinical outcome } & \multirow{2}{*}{$\begin{array}{l}\text { Follow up } \\
\text { (months) }\end{array}$} \\
\hline & Torcular & Jugular bulb & Torcular & Jugular bulb & Symptoms & Papilloedema & \\
\hline 1 & 45 & 8 & 23 & 8 & No change & Absent† & 26 \\
\hline 2 & 29 & 8 & 13 & 7 & Improved & Resolved & 24 \\
\hline 3 & 25 & 4 & 19 & 9 & No change & No change & 18 \\
\hline 4 & 25 & 7 & 13 & 9 & Asymptomatic & Improved & 18 \\
\hline *5 & 23 & 11 & 16 & 12 & No change & No change & 14 \\
\hline *6 & 15 & 7 & 14 & 11 & No change & Absent† & 14 \\
\hline 7 & 34 & 6 & 13 & 11 & Asymptomatic & Resolved & 12 \\
\hline 8 & 29 & 7 & 12 & 8 & Asymptomatic & Resolved & 12 \\
\hline 9 & 26 & 9 & 17 & 10 & Improved & Resolved & 14 \\
\hline 10 & 24 & 13 & 17 & 11 & Asymptomatic & Unknown & 2 \\
\hline 11 & 20 & 8 & 12 & 10 & Asymptomatic & Absent† & 9 \\
\hline 12 & 31 & 11 & 18 & 12 & No change & Absent† & 7 \\
\hline
\end{tabular}

They concluded that intracranial venous hypertension in IIH was largely irrelevant because it was secondary to raised intracranial pressure, and that the cause of raised intracranial pressure remained unsolved. But is this justified? It is widely understood that raised intracranial pressure caused by unequivocal cerebral venous thrombosis is relieved by CSF diversion. ${ }^{19}$ If such a procedure were accompanied by a reduction in intracranial venous pressure, then King's conclusions may not be appropriate.

Taking a different approach we found, in a patient with IIH also reported previously (case 2), that dilating one of these lateral sinus stenoses with a stent reduced the pressure gradient across it and reduced intracranial venous hypertension, effecting immediate clinical improvement which has been maintained. ${ }^{12}$ Moreover, follow up studies in this case confirmed a reduction in intracranial pressure. We concluded that venous outflow obstruction from lateral sinus stenoses was the cause of IIH in some patients and speculated that, given the difficulty of establishing the diagnosis of sinus stenosis, its role in the aetiology of IIH was probably underestimated.

Our present results support that view. Not all patients have benefited, but some have responded extremely well to stenting-though there is little intimation at this stage of the clinical criteria that predict a good outcome. Stented patients comprised a uniform group in that they all had a diagnosis of IIH unresponsive to treatment, but otherwise reflected the breadth of the clinical problem presented by this disorder. Some patients had visual disturbance and acute papilloedema; in others papilloedema had become chronic or had resolved. Some patients had a relatively short history; others had had debilitating symptoms for over a decade. Some had had no previous surgical intervention; others had had multiple neurosurgical procedures. None of these factors predicted the outcome of stenting. For example, in one patient (case 5) with symptoms for 12 years, stenting effected a $7 \mathrm{~mm} \mathrm{Hg}$ reduction in the sagittal sinus pressure but no clinical improvement. In another patient (case 4), of similar age and length of history, stenting effected a $12 \mathrm{~mm} \mathrm{Hg}$ reduction in sagittal sinus pressure and resolution of symptoms.

Equally, there was no consistent relation between venous pressure reductions and symptom relief, although there was a trend towards a greater reduction in pressure or lower sagittal sinus pressures with improvement (table 2). This led us, in two patients, to treat both sides (on separate occasions)-in one with further symptomatic improvement (case 2) and in the other with no change (case 3). This second patient has persistent moderately high venous pressures.

CSF diversion procedures in IIH are the mainstay of treatment after more conservative measures have failed. These reduce intracranial pressure but add little information about the pathogenic mechanisms responsible for the disease. If IIH were the result of overproduction of CSF, or of an absorptive block, then CSF shunting should be an effective treatment. If IIH were the result of idiopathic brain swelling, CSF drainage might act by reducing the size of the subarachnoid and intraventricular spaces. How CSF drainage operates in cerebral venous outflow obstruction is not understood, but its efficacy not disputed. ${ }^{19}$

The efficacy of stenting, on the other hand, is predicated on the notion that venous outflow obstruction plays some part in the aetiology of symptoms and signs in patients with IIH. If venous outflow obstruction were the cause, then dilating the stenosis and abolishing the pressure gradient should be curative. If the lateral sinus stenoses were secondary to raised intracranial pressure then, in patients in whom stenting was beneficial, these stenoses must have been responsible for a sufficient exacerbation of raised intracranial pressure to render them symptomatic. With seven patients improving after stenting, five very considerably, either one of these mechanisms must operate in a substantial proportion of patients with IIH. However, without post-stenting CSF pressure measurements (except in one instance, case 2), it is not possible to differentiate between them. With respect to patients who did not respond to stenting, either they represent a group where venous outflow obstruction was not the cause of raised intracranial pressure, or one where venous outflow obstruction has not been adequately relieved. By virtue of the anatomy, pressure gradients along both lateral sinuses were necessarily similar but most patients had only one side treated, often leaving a small residual gradient that might account for persistent symptoms.

What role stenting might have in the treatment of refractory IIH it is too early to say. Much will depend on the stability of the result, given the known tendency for restenosis around intravascular stents at other sites. ${ }^{2021}$ Regardless of this issue, however, with the morbidity and sometimes limited efficacy of current neurosurgical management $^{1}$ the prospect of a viable alternative is exciting. Moreover, the successful treatment of some patients by relief 
of venous outflow obstruction should encourage a revision of current concepts of IIH and its relation to venous sinus disease and sinus thrombosis.

\section{Authors' affiliations}

J N P Higgins, C Cousins, Department of Radiology, Addenbrooke's Hospital, Cambridge, UK

N Sarkies, Department of Ophthalmology, Addenbrooke's Hospital

J D Pickard, Academic Neurosurgical Unit, Addenbrooke's Hospital B K Owler, Department of Neurosurgery, Royal Prince Alfred Hospital, Camperdown, Sidney, Australia

Competing interests: none declared

\section{REFERENCES}

1 Sussman JD, Sarkies N, Pickard JD. Benign intracranial hypertension. Pseudotumour cerebri: idiopathic intracranial hypertension. Adv Tech Stand Neurosurg 1998;24:261-305

2 Donaldson JO. Pathogenesis of pseudotumor syndromes. Neurology 1981:31:877-80.

3 Fishman RA. Pathophysiology of pseudotumour cerebri. An unsolved puzzle [editorial]. Arch Neurol 1984;41:257-8.

4 Ray BS, Dunbar HS. Thrombosis of the dural venous sinuses as a cause of "pseudotumor cerebri". Ann Surgery 1951;134:376-86.

5 Janny $\mathbf{P}$, Chazal J, Colnet $G$, et al. Benign intracranial hypertension and disorders of CSF absorption. Surg Neurol 1981;15:168-74.

6 Medlock MD, Olivero WC, Hanigan WC, et al. Children with cerebral venous thrombosis diagnosed with magnetic resonance imaging and magnetic resonance angiography. Neurosurgery 1992:31:870-6.

7 Bouisse V, Ameri A, Bousser MG. Isolated intracranial hypertension as the only sign of cerebral venous thrombosis. Neurology 1999;53:1537-42.
8 Lee AG, Brazis PW. Magnetic resonance venography in pseudotumour cerebri. J Neuroophthalmol 2000;20:12-13.

9 King JO, Mitchell PJ, Thomson KR, et al. Cerebral venography and manometry in idiopathic intracranial hypertension. Neurology 1995;45:224-8.

10 Karahalios DG, Rekate HL, Khayata MH, et al. Elevated intracranial venous pressure as a universal mechanism in pseudotumor cerebri of varying etiologies. Neurology 1996;46:198-202.

11 King JO, Mitchell PJ, Thomson KR, et al. Manometry combined with cervical puncture in idiopathic intracranial hypertension. Neurology 2002;58:26-30.

12 Higgins JNP, Owler BK, Cousins C, et al. Venous sinus stenting for refractory benign intracranial hypertension. Lancet 2002;359:228-30.

13 Czosnyka $M$, Whitehouse $H$, Smielewski $P$, et al. Testing of cerebrospinal compensatory reserve in shunted and non- shunted patients: a guide to interpretation based on an observational study. I Neurol Neurosurg Psychiatry 1996;60:549-58.

14 Vogl TJ, Bergman C, Villringer A, et al. Dural sinus thrombosis: value of venous MR angiography for diagnosis and follow up. Am J Radiology 1994;162:1191-8.

15 Ayanzen RH, Bird CR, Keller PJ, et al. Cerebral MR venography: normal anatomy and potential diagnostic piffalls. Am J Neuroradiol 2000;21:74-8.

16 Huang YP, Okudera T, Ohta T et al. Anatomic variations of the dural venous sinuses. In: Kapp JP, Schmidek HH, eds. The cerebral venous system and its disorders. Orlando: Grune and Stratton, 1984:109-68.

17 Osterholm J. Reaction of the cerebral venous system to acute intracranial hypertension. J Neurosurg 1970;32:654-9.

18 Johnston I, Rowan J. Raised intracranial pressure and cerebral blood flow. 3.Venous oufflow tract and vascular resistances in experimental intracranial hypertension. J Neurol Neurosurg Psychiatry 1974;37:392-402.

19 Bousser MG, Ross Russell R. Cerebral venous thrombosis. London: WB Saunders Co, 1997:142-56.

20 Siskin GP, Englander M, Roddy S, et al. Results of iliac artery stent placement in patients younger than 50 years of age. J Vasc Interv Radiol 2002;13:785-90.

21 Schurmann K, Mahnken A, Meyer J, et al. Long-term results 10 years after iliac stent placement. Radiology 2002;224:731-8.

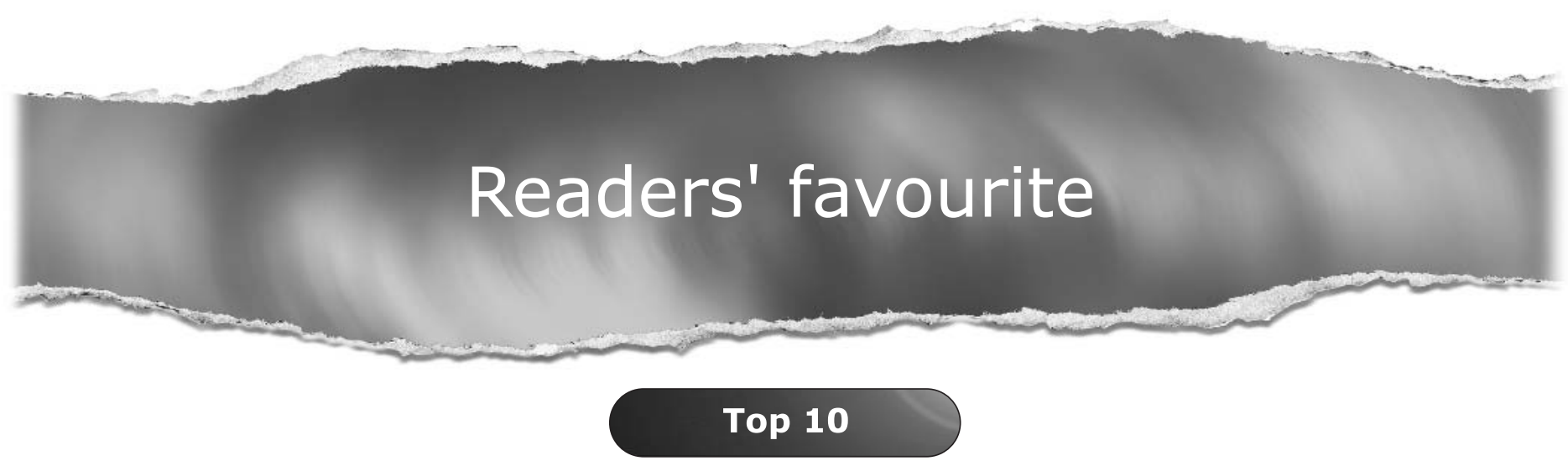

Click on the "Top 10" button on the homepage

to see which are the best read articles each month

www.jnnp.com 